\title{
Research on Influencing Factors of Online Shopping Under the Background of New Retail
}

\author{
Changlin Wang \\ Tianjin University of Commerce, Tianjin, China \\ Wcl_tuc@126.com
}

\begin{abstract}
This research focused on the emerging and existing important system information of ecommerce platform under the background of "new retail". Based on the stimulus-organism Response model and related theories, a situational questionnaire was used to analyze the process of mutual influence of perceived trust and perceived commodity quality on consumers ' purchasing decisions. Through the questionnaire survey method, empirical analysis under the background of the new retail factors affecting consumer purchase intention, and get the following conclusions. (1) In the context of e-commerce platform, the information quality and offline service level of online shop we Media have an impact on consumers' purchase intention through the perception of online shop trust. (2) The quality of product description and comments influences consumers' purchase intention not only by perceiving the quality of products, but also by perceiving the trust of online stores. (3) Perceived online store trust and perceived commodity quality are antecedent variables affecting consumers' shopping decisions, and perceived trust has a greater impact.
\end{abstract}

Keyword: New retail, SOR, Influence factors of Purchase Intention, Perceived trust

\section{Introduction}

After nearly ten years of rapid development, e-commerce platform has become an important engine of new economic development. However, with the disappearance of online demographic dividend and the upgrading of consumer demand, the competition between e-commerce platforms is becoming more and more fierce, and the cost of customer acquisition is getting higher and higher [1]. Therefore, in the context of new retail, e-commerce platforms have strengthened their competitive advantages and performance by integrating channels and using social media technologies. For example, Tmall not only provides traditional product description and product comment social media functions, but also adds offline store channel integration and micro-tao social media information service functions. The information is mainly descriptive and cognitive processing is laborious. Similar to some researches, this research defines it as e-commerce platform system information. How to understand the impact of these system information on consumers' shopping decisions has become a common concern of ecommerce platforms and merchants [2].

Existing researches mainly explore the influence of trust or product evaluation on consumers' shopping decisions on overall quality characteristics of websites such as website quality and information quality or traditional characteristics such as brand, reputation and third-party

Article history:

Received (February 8, 2020), Review Result (March 15, 2020), Accepted (April 18, 2020) 
identification under the traditional e-commerce environment. For example, the paper [3] analyzed the quality of e-commerce websites and website brands based on Stimulus-OrganismResponse (SOR) model. These two online environmental cues, mediated by perceived trust and risk, have an impact on consumers' purchase intention. Similarly, the paper [4] explores the characteristics of website information quality, third-party trust identification and reputation, and the impact of perceived trust and risk on consumers' purchase intention of websites. This paper [5] analyzes the influence of product quality perception on consumers' purchase intention from the perspective of signal theory. This paper [6] analyzes the influence of seller's reputation and commodity description on product evaluation based on clue utilization theory. Based on the theory of rational behavior, this paper [7] reveals the influence of comment quality on consumers' purchase intention.

This research will focus on the emerging and existing important system information of ecommerce platform under the background of "new retail". Based on the stimulus-organism Response model and related theories, a situational questionnaire was used to analyze the process of mutual influence of perceived trust and perceived commodity quality on consumers' purchasing decisions.

\section{Relevant theories and research hypotheses}

\subsection{System information of e-commerce platform}

Heuristic-Systematic Model (HSM) is an important theory in recent years to explain how individuals process information, establish effectiveness evaluation and form decision-making [8]. The theory points out that individuals in high-risk decision-making environments may have the intention and motivation to make more mental efforts to collect and process information, that is, to make decisions by relying on systematic methods. E-commerce retail platforms that adopt the settled business model usually gather a large number of different sellers selling the same kind of goods. In addition to a few flagship stores of well-known brands, most of them are unknown online stores. Under the network environment, consumers can not personally inspect and experience the quality of goods, so the transaction risk is greater. Therefore, consumers often need to integrate a variety of information clues to evaluate retailers and goods. In the traditional e-commerce environment, two kinds of information clues, seller description and consumer comment, have attracted the attention of researchers and are considered to have a great influence on consumers' shopping decisions. Under the background of "new retail", with the integration of the application of social media technology and online and offline channels, we media information and offline service information have become important service ability clues for retailers. However, relevant researches are relatively lacking. This information is the important system information of e-commerce platform retailer and commodity level.

The stimulus-response model, originated from the field of environmental psychology, is a classical model for studying the online retail environment and consumer behavior [9]. According to this theory, the stimulation of e-commerce platform environment will affect consumers' internal cognition and emotional perception, and then affect consumer behavior. We media information and offline service information at the retailer level, seller description and consumer comment information at the commodity level can be regarded as external stimuli. Perceived trust and perceived quality of goods are consumers' internal perception, and consumers' purchase intention is a response factor.

\subsection{Research Hypothesis}




\subsubsection{Influence of services on perceived trust and perceived commodity quality}

Offline service level and we media information quality are important service ability clues for platform retailers. Under the background of "new retail" integrating online and offline, there are two forms of online shop: one is only engaged in online business, and the other has both online and offline business forms. Online stores with two business forms can, on the one hand, provide offline businesses with shopping experience and services that cannot be realized online to enhance users' trust. On the other hand, reputation and trust built through offline business can be transferred to online business. Therefore, the offline business of online stores can be seen as an important way for them to build trust. Studies have found that offline business of merchants can increase users' trust in community online-to-offline $(\mathrm{O} 2 \mathrm{O})$ e-commerce.

With the development of social commerce, e-commerce platforms are increasingly integrated into social media technologies. E-commerce has launched we-media functions similar to microblog and blog, etc. For example, the store dynamics of Taobao micro-tao and Jingdong Mall can release relevant information about store activities, product knowledge and user feedback at any time. These can reflect the information quality of information update timeliness, content and user demand correlation, describe the level of true reliability, reflect the shop's service ability. Information quality is an important factor affecting trust in traditional and social e-commerce websites. As an important part of online store information content in the context of social e-commerce, the quality of we-media information may also affect consumers' trust in online stores [10].

In addition, given the characteristics of the network market, consumers cannot directly understand the quality of goods through on-site perception, and can only judge by external signal clues. Website quality is an important external signal clue of commodity quality perception under the traditional e-commerce environment. As an important part of the quality of online stores, retailer strength clues can be regarded as the external quality signal clues that influence consumers' perception of the quality of goods.

Based on the above analysis, in the context of e-commerce platform, the following assumptions are proposed:

H1a: Perception of offline service level has a significant positive impact on perceived trust of online stores.

H1b: Perception of offline service level has a significant positive impact on perceived product quality.

$\mathrm{H} 2 \mathrm{a}$ : Online shop we media information quality perception has a significant positive impact on online shop perceived trust;

$\mathrm{H} 2 \mathrm{~b}$ : Perception of information quality of online shop we media has a significant positive impact on perceived commodity quality.

\subsubsection{Influence of commodity comment quality on perceived trust and perceived commodity quality}

The quality of product reviews reflects the characteristics associated with the content of product reviews and is usually defined as the persuasive nature of the content of the message [11]. High-quality commodity review information can clearly reflect the attitude of the reviewer and explain why and how the particular attitude of the reviewer towards the target has been formed. The evidence used to support the reviewer's views is often clear and specific. The lowquality review information contains only the subjective feelings of the reviewer, without any evidence of product quality. The quality of comment has the characteristics of effective valence 
as well as of persuasion strength. In order to control the effect of comment titer, positive comments were used in all comments in this study. Therefore, the higher the quality of the comment information, the more sufficient the argument, and the more specific the commodity attribute information reflected, the more conducive to the adoption and positive perception of commodity quality. While revealing the attributes of commodity quality, the content of commodity reviews also contains clues of trust such as retailer's ability, honesty and goodwill. Positive and persuasive commodity reviews help to enhance consumers' trust in retailers. Empirical research finds that improving the quality of reviews can improve consumers' trust in e-commerce sites [12].

Based on the above analysis, the following assumptions are proposed in the context of ecommerce platform:

H3a: Perceived quality of product reviews positively affects perceived trust of online stores;

$\mathrm{H} 3 \mathrm{~b}$ : Perceived quality of commodity comment positively influences perceived quality of commodity.

\subsubsection{The influence of commodity description quality on perceived trust and perceived commodity quality}

Commodity description information is the description of the basic attributes, functions and values of commodities provided by online stores. The quality of commodity description refers to consumers' evaluation of the degree to which the commodity description information meets their own needs. The commonly used evaluation indexes include comprehensiveness, vividness, relevance and accuracy. When shopping online, consumers cannot touch and try products. The product description information provided by online stores is an important reference for consumers to perceive the product quality and make judgments based on it. The richer, more relevant and more accurate commodity description information is, the more helpful it is for consumers to accurately judge the commodity attributes and the degree of conformity with their own needs, increase their expectation of commodity quality, and reduce the uncertainty before purchase. Some empirical studies also show that diversified online product presentation mechanisms contribute to consumer product perception. The richer the online product display, the more helpful it is to increase consumers' understanding of the product and reduce their perception of product quality uncertainty [13]. In addition, as an information service provided by the online shop, the description quality reflects the service ability, integrity and goodwill of the online shop, which is similar to the website information quality for the website credibility. The description quality can be used as an important external signal clue for the credibility of the online shop.

Based on the above analysis, the following hypotheses are proposed:

H4a: Product description quality perception positively affects online store perceived trust;

H4b: Product description quality perception positively affects perceived product quality.

\subsubsection{Perceived trust, perceived quality and purchase intention}

As a social phenomenon, trust has been widely concerned by many disciplines. It reflects the expectation of one party to the other that the other party will not take advantage of one's weakness and dependence to adopt opportunistic behaviors, but will act in a reliable, moral and socially beneficial and appropriate way to fulfill its commitments. Trust in this study refers to consumers' willingness to believe that online stores on the platform are honest, reliable and good-faith, which reflects the extent to which consumers believe that online stores can fulfill their promises and refrain from opportunistic behaviors. Perceived commodity quality refers to 
consumers' evaluation of the excellence or superiority of commodity attributes. According to the degree of information asymmetry, commodity attributes can be divided into search attributes, experience attributes and trust attributes. Among them, the experience attribute is difficult to identify before online shopping, and the trust attribute is difficult to confirm even after purchase. Obviously, the higher the degree of trust consumers have in an online store, the more they believe that the store will act in an ethical and honest way during the sales process, thus increasing their perception of the product experience gained from the transaction and the quality of trust attributes. On the contrary, in the face of an untrusted online retail store, consumers are likely to have doubts, believing that online retail stores may brag about the quality of products in the description and promotion in order to promote sales, and fail to fulfill their promises on the quality of products. The paper [14] finds that perceived trust on ecommerce websites has a positive impact on perceived commodity quality.

In the network environment with transaction risk, trust is an important determinant to influence consumers' purchase intention. The paper [15] points out that trust in online retailers is the most influential predictor of consumers' buying intentions. This paper [16] finds through empirical research that perceived trust has a significant impact on the purchase intention of potential and repeated consumers of book websites. The paper [17] points out that trust in online retailers plays a fully mediating role in the impact of performance risk on consumers' buying intentions.

Perceived quality of goods can also influence buying intentions. According to the theory of rational behavior, the attitude towards the target in a certain situation is the key antecedent that affects the behavioral intention. Perceived quality of goods, as a measure of attitude towards goods, may affect consumers' purchase intention of the goods. In the online retail environment, empirical studies have found that perceived product quality positively affects consumers' intention to purchase products through websites.

Based on the above analysis, the following assumptions are proposed in the context of ecommerce platform:

H5: Online store perceived trust has a positive influence on perceived commodity quality.

H6: Online store perceived trust has a positive influence on purchase intention.

H7: Perceived commodity quality has a positive influence on consumers' purchase intention.

\subsubsection{Control variables}

Personal trust tendency refers to the psychological tendency of a person to be willing to rely on others under different circumstances, which determines the degree to which a person is willing to accept the information provided by others. Some studies suggest that the trust tendency should be included as a control variable in the empirical study of the trust model. Therefore, this study takes trust tendency as the control variable to control its influence on perceived trust.

\section{Research design}

\subsection{The questionnaire design}

In this study, the situational questionnaire survey method is adopted to conduct model and hypothesis testing. This method integrates the advantages of the experimental method and the questionnaire survey method, and enables the interviewees to fill in the questionnaire under a given decision-making scenario. This method can overcome the limitation of traditional 
questionnaire survey and obtain more effective sample data. Scenario design manipulates retailer strength and commodity characteristic information.

\subsubsection{Scenario design}

Considering that it is difficult to overcome consumers' bias by using a real enterprise as the research object, a virtual online store is used as the decision-making scenario. The choice of smart bracelet is mainly based on the following considerations: First, with the penetration of the Internet into all walks of life, more and more people begin to choose and buy wearable products, and the online sales volume of smart bracelets is increasing year by year. Second, the smart bracelet has numerous functions and large price range. Most people have great uncertainty in the purchase process, and consumers are more inclined to make purchase decisions by using various web page information clues.

In order to ensure appropriate variation of independent variables, eight specific shopping scenarios were created for the three variables of online store service ability, product comment quality and product description quality according to the high and low levels. The service ability of the online shop is controlled by the information quality of the online shop "we media" and the offline service level. If the service ability is high, both of them are high; if the service ability is low, both of them are low. The quality of online store we-media information is manipulated through the relevance, diversity, timeliness and usefulness of we-media information. Offline service level is controlled by offline service identification. Quality reviews are relevant to the product, easy to understand and persuasive. Low-quality comments are emotional, subjective and empty. High quality description specification parameters comprehensive, illustrated, easy to read, multimedia display. The low-quality descriptions are not easy to read and are mainly text displays. All situational information is adapted from the real e-commerce platform, and information unrelated to the research objective, such as sales volume, evaluation quantity, store reputation, etc., is hidden.

\subsubsection{Measurement of constructs}

In the empirical model of this study, the measurement indicators of constructs are mainly based on the previously proposed and verified scales. Then, it is adapted appropriately according to the specific situation of this study. All constructs were measured by Likert scale.

Table 1. Measuring index and factor loading

\begin{tabular}{|c|c|c|}
\hline \multirow{2}{*}{ Concept } & Measurement problems & Factor Loading \\
\hline \multirow{3}{*}{$\begin{array}{c}\text { We Media } \\
\text { information } \\
\text { quality }\end{array}$} & we media information update very quickly & 0.882 \\
\cline { 2 - 3 } & We media information is related to my needs & 0.881 \\
\cline { 2 - 3 } & We media information is sufficient & 0.922 \\
\hline \multirow{2}{*}{$\begin{array}{c}\text { Offline } \\
\text { service } \\
\text { quality }\end{array}$} & We media information is reliable & 0.858 \\
\cline { 2 - 3 } & Ot is convenient to enjoy the offline experience service in the shop & 0.927 \\
\hline \multirow{3}{*}{$\begin{array}{c}\text { Product } \\
\text { review } \\
\text { quality }\end{array}$} & The product reviews are relevant to my purchase decision & 0.939 \\
\cline { 2 - 3 } & Product reviews are objective in content & 0.928 \\
\cline { 2 - 3 } & The product reviews are comprehensive & 0.769 \\
\cline { 2 - 3 } & The content of product reviews is persuasive & 0.805 \\
\hline
\end{tabular}




\begin{tabular}{|c|c|c|}
\multirow{4}{*}{$\begin{array}{c}\text { Description } \\
\text { of goods } \\
\text { quality }\end{array}$} & The product description information is detailed enough & 0.893 \\
\cline { 2 - 3 } & The product description information is visually pleasing & 0.861 \\
\cline { 2 - 3 } & The product description information is well organized & 0.922 \\
\hline \multirow{3}{*}{$\begin{array}{c}\text { Sense of } \\
\text { trust }\end{array}$} & The product description information is comprehensive & 0.912 \\
\cline { 2 - 3 } & The shop is generally honest & 0.879 \\
\hline \multirow{2}{*}{$\begin{array}{c}\text { Perception } \\
\text { of product } \\
\text { quality }\end{array}$} & The shop is generally reliable & 0.945 \\
\cline { 2 - 3 } & The shop is generally trustworthy & 0.934 \\
\hline \multirow{3}{*}{$\begin{array}{c}\text { Purchase } \\
\text { intention }\end{array}$} & I think this product is durable & 0.87 \\
\cline { 2 - 3 } & I think the product is well designed & 0.883 \\
\hline \multirow{2}{*}{$\begin{array}{c}\text { Trust } \\
\text { tendency }\end{array}$} & I think the product is of high quality & 0.919 \\
\cline { 2 - 3 } & I'm very likely to buy this product & 0.91 \\
\cline { 2 - 3 } & I will consider buying this product & 0.884 \\
\cline { 2 - 3 } & I am willing to purchase this product & 0.922 \\
\hline
\end{tabular}

\subsection{Data collection and samples}

The subjects of this study are people with online shopping experience. In order to get closer to the survey target, the network survey method is adopted to collect data. March 21, 2019 solstice April 18, 2019, after four weeks of online polling. Finally, 523 valid questionnaires were obtained to meet the minimum sample size required for structural equation model analysis. The descriptive statistical analysis of the samples showed that the sample size of the eight questionnaires ranged from 27 to 36, and the distribution was relatively balanced. 197 (37.7\%) males and $326(62.3 \%)$ females were the majority. The main age groups were 20 29 years old $(46.3 \%)$ and 30 39 years old (29.4\%). Most of the students received college or university degrees $(71.7 \%)$. The sample with more than two years of shopping experience accounted for more than $80 \%$. Compared with the description of the characteristics of Internet users in the Statistical Report on the Development of Internet in China released by China Internet Network Information Center, the samples are representative to some extent.

Since the data in this study were collected from a single source simultaneously, the common method bias problem was further tested. First, Harmon's univariate method was used to test the constructs in the study model. The results show that there are eight factors, and the maximum variance of one factor explanation is $34.49 \%$, indicating that the threat of common method bias is in the acceptable range. Secondly, referring to the research in the paper [18], common method factors and indicators of all major constructs were incorporated into the partial least square (PLS) model, and then their respective interpretations of variance for each indicator were calculated. The results showed that the mean variance explained by the substantive constructs of each indicator was 0.78 , and that explained by the common method factors was less than 0.01 , indicating that the mean variance explained by the common method factors accounted for a very small proportion. In addition, the factor loading values of most common methods are very small and most of them are not significant, indicating that there is no serious common method deviation problem in the samples.

Further test the effectiveness of scenario control variable manipulation. The control level of situational variables (high or low) is taken as independent variable, and the mean value of the 
corresponding measurement index of situational variables is taken as dependent variable. Analysis of variance was conducted for the quality of online shop "we Media" information, offline service level, product comment quality and product description quality. The results showed that the differences between high and low levels of situational variables were significant at $\mathrm{p}<0.001$, indicating that the manipulation was effective.

\section{Model analysis}

The constructs in this study are relatively complex, and some of them are exploratory studies. Kolmogorov-smirnov test showed that each construct measurement index did not conform to the normal distribution. At the same time, the control variables need to be processed, so the partial least squares structural equation model (PLS-SEM) analysis method was selected.

\subsection{Measurement model analysis}

SmartPLS3.0 software was used to verify the reliability and construct validity of the measurement model. The results are shown in [Table 2]. The Cronbach's coefficient of all constructs varied from 0.84 to 0.92 , and the $\mathrm{CR}$ value of the combined reliability ranged from 0.89 to 0.95 , all of which were higher than the threshold value of 0.7 , indicating that the measurement model had good internal consistency reliability. The average variance extracted value (AVE) of constructs ranged from 0.67 to 0.87 , higher than the threshold value of 0.5 , and the variation range of factor load of all measurement indicators was 0.766 to 0.945 , all larger than the threshold value of 0.6 , and significant at the level of $\mathrm{P}<0.001$, indicating that the measurement model also had good convergence validity. The maximum value of the construct correlation coefficient is 0.69 , less than the square root of the extracted value of the mean variance of any construct. All indicator factor loads were greater than their cross loads on other constructs, and the heterogeneity - homogeneity correlation ratio (HTMT) was as high as 0.774 . All of them were lower than the threshold value of 0.90, indicating that the measurement model in this study has significant discriminant validity.

Table 2. Inspection results

\begin{tabular}{|c|c|c|c|c|c|}
\hline Influence path & $\begin{array}{c}\text { Path } \\
\text { coefficient }\end{array}$ & $\begin{array}{c}\text { Standard } \\
\text { deviation }\end{array}$ & p values & $\begin{array}{c}\text { Corresponding } \\
\text { hypothesis }\end{array}$ & $\begin{array}{c}\text { Path } \\
\text { significance }\end{array}$ \\
\hline $\begin{array}{c}\text { Online store offline service } \\
\text { level } \rightarrow \text { perceived trust }\end{array}$ & 0.109 & 0.054 & 0.043 & H1a & significan \\
\hline $\begin{array}{c}\text { Online shop we media } \\
\text { information quality } \rightarrow \\
\text { perceived trust }\end{array}$ & 0.191 & 0.064 & 0.003 & H2a & significan \\
\hline $\begin{array}{c}\text { Online shop offline service } \\
\text { level } \rightarrow \text { perceived quality } \\
\text { of goods }\end{array}$ & -0.012 & 0.049 & 0.813 & H1b & significant \\
\hline $\begin{array}{c}\text { Online shop we media } \\
\text { information quality } \rightarrow \\
\text { perceived quality of goods }\end{array}$ & 0.029 & 0.052 & 0.581 & H2b & non- \\
\hline $\begin{array}{c}\text { Product review quality } \rightarrow \\
\text { perceived trust }\end{array}$ & 0.329 & 0.045 & 0 & H3a & significant \\
\hline
\end{tabular}




\begin{tabular}{|c|c|c|c|c|c|}
$\begin{array}{c}\text { Product review quality } \\
\text { Perception of product } \\
\text { quality }\end{array}$ & 0.326 & 0.049 & 0 & H3b & significan \\
\hline $\begin{array}{c}\text { Product description quality } \\
\rightarrow \text { perceived trust }\end{array}$ & 0.156 & 0.044 & 0 & H4a & significan \\
\hline $\begin{array}{c}\text { Product description quality } \\
\rightarrow \text { perception of product } \\
\text { quality }\end{array}$ & 0.181 & 0.038 & 0 & H4b & significan \\
\hline $\begin{array}{c}\text { Perceived trust } \rightarrow \\
\text { perceived commodity } \\
\text { quality }\end{array}$ & 0.365 & 0.048 & 0 & H5 & significan \\
\hline $\begin{array}{c}\text { Perception trust } \rightarrow \\
\text { purchase intention }\end{array}$ & 0.446 & 0.052 & 0 & H6 & significan \\
\hline $\begin{array}{c}\text { Perception of product } \\
\text { quality } \rightarrow \text { purchase } \\
\text { intention }\end{array}$ & 0.299 & 0.051 & 0 & H7 & significan \\
\hline $\begin{array}{c}\text { Trust tendency } \rightarrow \\
\text { perceived trust }\end{array}$ & 0.108 & 0.04 & 0.007 & & \\
\hline
\end{tabular}

\subsection{Structural model inspection}

\subsubsection{Model validity test}

The main criteria for validity assessment of structural models are determination coefficient $\left(\mathrm{R}_{2}\right)$ and forecast correlation $\left(\mathrm{Q}_{2}\right)$. Where, $\mathrm{R}_{2}$ represents the explained variance of each endogenous latent variable, and its value reaches 0.33 , indicating that the explanatory ability reaches medium level, while 0.67 represents strong explanatory ability. $\mathrm{Q}_{2}$ is used to test the predictive relevance of the model. In general, the model's endogenous construct $\mathrm{Q}_{2}$ is greater than 0 , indicating that the model has predictive relevance.

SmartPLS3.0 software was used for analysis, and the R2 of the three constructs of perceived commodity quality, purchase intention and perceived trust were $0.472,0.615$ and 0.481 respectively, all greater than 0.33 , indicating that the model as a whole had a medium level of interpretation. The $\mathrm{Q}_{2}$ of the three constructs of perceived commodity quality, purchase intention and perceived trust were $0.364,0.456$ and 0.378 respectively, which were all greater than 0 , indicating that the model had predictive correlation.

\subsubsection{Hypothesis testing}

The significance of model path coefficient was calculated using Bootstrap-ping method of SmartPLS3.0 software and the number of repeated sampling was set to 5,000. The results are shown in [Table 2]. [Table 2] shows that there are 11 hypotheses of direct impact effect in this study, among which 2 fail to pass the test and 9 pass the test. The influence of control variables is significant.

\section{Conclusions and Implications}

\subsection{Results and discussion}


In this study, the selection of smart bracelet was taken as the decision-making scenario. Situational questionnaire survey was adopted. Taking trust and commodity quality perception as intermediaries, this paper empirically analyzes the influence of systematic information clues at the retailer level and commodity level on consumers' purchase intention. The following conclusions:

(1) In the context of e-commerce platform, the information quality and offline service level of online shop we Media have an impact on consumers' purchase intention through the perception of online shop trust

The paper [19] found that the perception of social media marketing activities on e-commerce websites can significantly improve consumers' purchase intention. The paper [20] points out that the effective use of social media technology in Taobao.com can increase consumers' trust in online stores. The paper [21] found that consumers with high risk perception are more likely to use offline in-store pickup services during online shopping. This study further reveals the influence mechanism of online shop we Media technology and offline services on consumers' shopping intentions, and expands the above research conclusions in new situations. It provides empirical evidence for the current practice of integrating social media and offline services on e-commerce platforms.

However, the information quality of online "we media" and offline service level have no significant influence on perceived product quality. The reason may be that they are weak commodity quality signals compared with commodity description and comment signal cues, resulting in less impact. This is because, according to the study of signal theory, in the presence of multiple signals, a strong signal will weaken the effect of other signals. For example, some studies have found that when there is a large amount of direct commodity information, the impact of price on perceived quality will be weakened.

(2) The quality of product description and comments influences consumers' purchase intention not only by perceiving the quality of products, but also by perceiving the trust of online stores

Product quality evaluation is a major task of online shopping decision making. Based on the signal theory, the paper [5] established a research model of the influence of external clues of website quality on consumers' purchase intention through influencing perceived commodity quality. This study expands the model from the specific dimension of website quality and the perspective of trust theory. Identify the two most important online quality cues: description quality and comment quality. It is pointed out that the trust and the perception of commodity quality are the important intermediary factors that the quality clues of the online shop affect the consumers' shopping decisions.

(3) Perceived online store trust and perceived commodity quality are antecedent variables affecting consumers' shopping decisions, and perceived trust has a greater impact

This shows that in the e-commerce platform trading environment, although the platform reduces the risks of trading through measures such as trading rules, service guarantee and merchant qualification certification, it is still difficult to avoid transaction uncertainties such as commodity quality. For example, according to the e-commerce user experience and complaint monitoring report released by the E-commerce Research Center, commodity quality has been a hot issue for complaints in 2019. As a key strategy to deal with the uncertainty and risk of online environment, trust plays an important role in the purchase intention of e-commerce platform consumers.

\subsection{Suggestions}


When purchasing high-value goods online, consumers will perceive the credibility and quality of goods online by integrating various system information such as we-media information quality, offline service level, product description and comment quality, etc., so as to form purchasing decisions. Therefore, in order to improve the rate of traffic conversion, ecommerce platforms and online stores can start from the quality of "we Media" information service at the merchant level, the service level of offline stores, and the comment and description information quality at the commodity level, so as to improve consumers' trust in online stores and form a positive evaluation of goods.

For e-commerce platforms, attention should be paid to the development and improvement of social networking, online and offline interaction, commodity comment and commodity description service functions to provide convenience for the transmission of trust and quality signals and consumer perception of online stores. For example, improve the we-media function of online stores, so that consumers can not only respond to the content published by online stores, but also independently release brand and product experience information. Provide offline store management services to enable online stores to integrate online and offline product, inventory, price, promotion, trading, review and other information, and provide interactive services such as information inquiry, customer service, payment and order fulfillment; Introduce multi-dimensional, virtual reality and other emerging commodity display and experience technology, enrich the online store product description media; We will allow consumers to vote for high-quality reviews and give them priority in displaying them. We will apply big data technology to improve the ability to discriminate against behaviors such as brushing, false reviews and false advertisements, increase penalties for corresponding violations, and improve the information.

For retail stores, they should actively apply the functions of social media, offline services, product description and comment provided by the platform in combination with their own characteristics, marketing objectives and conditions, so as to increase consumers' trust in the stores and their perception of product quality. For example, communication and interaction with consumers can be strengthened in the form of dialogue, storytelling, customer interaction and personification to improve the diversity, timeliness and usefulness of social media information to consumers. Integrate online and offline promotion, product and price, trading, customer service and other information, and improve the online and offline comprehensive service capability through convenience and personalized service; Give play to the unique advantages of video, image, text and other media in information communication, display commodity attributes and characteristics comprehensively, vividly and objectively, so that consumers can perceive the fit of commodity quality attributes and characteristics with their own needs; On commodity management not only to get positive reviews, but also encourage consumers to reflect quality of the commodity specific attribute of the review, through to identify the best goods comments and share with customers on a regular basis, help them to generate higher quality review, at the same time pay attention to the best comment on the publisher to give appropriate incentives.

\section{Reference}

[1] Gwijeong Park, "Is consumer's rooming behavior good or bad for retailers? - focusing on shopping value of global consumers -," International Journal of Advanced Science and Technology, vol.117, pp.151-162, (2018) DOI:10.14257/ijast.2018.117.13 
[2] Meiliyah Ariani, Zulhawati, "Effect of easy transaction, consumer interests, and systems security level measures against fraud online shopping in Lazada," International Journal of Security and Its Applications, vol.10, no.12, pp.189-206, (2016) DOI:10.14257/ijsia.2016.10.12.15

[3] Chang H. H. and Chen S. W., "The impact of online store environment cues on purchase intention," Online information review, vol.32, no.6, pp.818-841, (2008)

[4] Kim D J, Ferrin D L, Rao H R, "A trust-based consumer decision-making model in electronic commerce: the role of trust,perceived risk, and their antecedents," Decision support systems, vol.44, pp.544-564, (2008)

[5] Wells J D, Valacich J S, and Hess T J., "What signal are you sending? how website quality influences perceptions of product quality and purchase intentions," MIS quarterly, vol.35, no.2, pp.373-396, (2011)

[6] Wang Q, Cui X, and Huang L, et al., "Seller reputation or product presentation? An empirical investigation from cue utilization perspective,” International journal of information management, vol.36, no.3, pp.271-283.

[7] Lee E J and Shin S Y., "When do consumers buy online product reviews? effects of review quality,product type, and reviewer's photo,"Computers in human behavior, vol.31, no.1, pp.356-366, (2014)

[8] Chaiken S. "Heuristic versus systematic information processing and the use of source versus message cues in persuasion," Journal of personality \& social psychology, vol.39, no.5, pp.752-766, (1980)

[9] Sabah Mohammed, Jinan Fiaidhi, and Sami Mohammed, "Thick data analytics: a human centric approach for understanding consumer insights," International Journal of Control and Automation, vol.12, no.2, pp.27-32, (2019) DOI:10.33832/ijca.2019.12.2.03.

[10] Kim S and Park H. "Effects of various characteristics of social commerce ( s- commerce ) on consumers'trust and trust performance," International journal of information management, vol.33, no.2, pp.318-332, (2013)

[11] Cheung C M K and Thadani D R. "The impact of electronic word- of- mouth communication : a literature analysis and integrative model,’Decision support systems, vol.54, pp.461-470, (2012)

[12] Lin X,Wang X,Hajli N., "Building e-commerce satisfaction and boosting sales : the role of social commerce trust and its antecedents," International journal of electronic commerce, vol.23, no.3, pp.328-363, (2019)

[13] Dimoka A,Hong Y, and pavlou P A, "On product uncertainty in online markets : theory and evidence," MIS quarterly,vol.36, no.2, pp.1-32, (2012)

[14] Mavlanova T, Benbunan- fich R, and Lang G., "The role of external and internal signals in e-commerce," Decision support systems, vol.87, pp.59-68, (2016)

[15] Pavlou P A., "Consumer acceptance of electronic commerce : integrating trust and risk with the technology acceptance model," International journal of electronic commerce, vol.7, no.3, pp.101-134, (2003)

[16] Kim H W, Xu Y, and Gupta S. "Which is more important in Internet shopping, perceived price or trust?’.Electronic commerce research \& applications, vol.11, no.3, pp.241-252, (2012)

[17] Hong I B and Cha H S., "The mediating role of consumer trust in an online merchant in predicting purchase intention," International journal of information management, vol.33, no.6, pp.927-939, (2013)

[18] Liang H, Saraf N, and Hu Q, et al. "Assimilation of enterprise systems : the effect of institutional pressures and the mediating role of top management," MIS quarterly, vol.1, no.1, pp.59-87, (2007)

[19] Yadav M, and Rahman Z. "Measuring consumer perception of social media marketing activities in e-commerce industry: scale development and validation," Telematics \& informatics, vol.34, no.7, pp.1294-1307, (2017)

[20] Chong A Y L,Lacka E, and Li B,et al. "The role of social media in enhancing guanxi and perceived effectiveness of ecommerce institutional mechanisms in online marketplace," Information \& management, vol.55, no.5, pp.621-632, (2018)

[21] Kim E, Park M C, Lee J., "Determinants of the intention to use Buy-Online,Pickup in-Store ( BOPS ) : the moderating effects of situational factors and product type," Telematics \& informatics, vol.34, no.8, pp.17211735, (2017) 